\title{
Experimental Study on Deformation Behavior and Compressive Strength of Concrete Cast in Steel Tube Arches under Low-Temperature Conditions
}

\author{
Tuo Shi $\mathbb{D}$, ${ }^{1,2}$ Nianchun Deng $\mathbb{D}^{1,2}$ Xiao Guo, ${ }^{1,2}$ Wen $X u^{3}$ and Shi Wang $\mathbb{D}^{4}$ \\ ${ }^{1}$ College of Civil Engineering and Architecture, Guangxi University, Nanning 530004, China \\ ${ }^{2}$ Key Laboratory of Disaster Prevention and Structural Safety of Ministry of Education, Guangxi University, \\ Nanning 530004, China \\ ${ }^{3}$ Subote New Materials Co. Ltd, Nanjing 211103, China \\ ${ }^{4}$ Tibet Railway Construction Co. Ltd, Lasa 851400, China \\ Correspondence should be addressed to Nianchun Deng; dengnch@gxu.edu.cn
}

Received 26 July 2019; Revised 9 October 2019; Accepted 2 November 2019; Published 6 February 2020

Academic Editor: Georgios Maliaris

Copyright (C) 2020 Tuo Shi et al. This is an open access article distributed under the Creative Commons Attribution License, which permits unrestricted use, distribution, and reproduction in any medium, provided the original work is properly cited.

\begin{abstract}
Taking the construction of a concrete-filled steel tube (CFST) arch bridge (part of the Sichuan-Tibet Railway) in low temperatures as the test site, firstly the deformation performance test of concrete was carried out. Following this initial testing, measurement of compressive strength and shrinkage performance was conducted in large-diameter CFSTs under a variety of curing conditions. Experimental results showed that the expansion effect of $\mathrm{Ca}-\mathrm{Mg}$ composite expansive agent in concrete was better than that of other expansive agents at any stage. Under low-temperature curing $\left(0^{\circ} \mathrm{C}\right)$, the sampling strength of the large-diameter CFSTs reached $73.5 \%$ of the design strength at $28 \mathrm{~d}$ in the presence of a nonthermal curing system. The design strength itself was reached, when a curing system involving a thermal insulation film was applied, and use of this film also led to improvements in concrete shrinkage. The results suggested that a Ca-Mg composite expansive agent, combined with an insulation film curing system, should be the technique selected for concrete pumping construction of CFST arch bridges in Tibet.
\end{abstract}

\section{Introduction}

Constructing bridges with the use of concrete-filled steel tube (CFST) arches is a rapidly developing technique in China and is blessed with clear economic advantages when used in certain span sizes [1,2]. High-performance concrete had also been used in the construction [3]. The average temperature in Tibet is relatively low because of the high altitude and the large amount of mountain and canyon, and the CFST arch bridge can exhibit a strong adaptability when the construction in extreme low temperature is inevitable. Arch rib concrete construction of CFST arch bridges is the key technology in arch bridge construction, in which the strength and compactness of concrete in pipes is one of the important indexes of safety and durability in arch bridges. The research on the development law of deformation performance and strength of concrete in pipes under low temperatures can provide basis for the selection of construction time and concrete material in pipes of CFST arch bridges in Tibet. Much research has been conducted in relation to the strength of concrete cured at low temperatures.

Marzouk and Hussein [4] tested the compressive strength of high-strength concrete at different curing temperatures and found it was proportional to curing temperature. Khatib [5] studied the effect of low-temperature curing on the compressive strength of metakaolin concrete and found that, under low-temperature curing conditions, an optimized amount of metakaolin could both increase the concrete's strength and reduce shrinkage. Barna et al. [6] found that concrete that was cured at low temperatures with an antifreeze agent could satisfy working requirements, while Consoli et al. [7] reported that increased curing temperature could improve the compressive strength and 
splitting tensile strength of sand/coal/fly ash/lime blends. ElHassan et al. [8] studied the properties of alkali-activated slag concrete under different curing systems and found that indirect water curing could improve the compressive strength, while Zhang et al. [9] found that raising curing temperature from $5^{\circ} \mathrm{C}$ to $50^{\circ} \mathrm{C}$ accelerated cement hydration. Charles Korhonen [10] concluded that the standards for cryogenic admixtures developed and endorsed by the American Society of Civil Engineering should be widely applied. Jiang et al. [11] optimized the mix ratio of C50 concrete and adopted temperature control measures during construction to the point that he developed a negative temperature construction technology for C50 concrete and successfully applied it to bridge construction in winter. Dong et al. [12] studied the compressive properties of new antifreezing concrete, cured at different subzero temperatures, and considered that the strength of the concrete made with the new antifreezing agent complied with relevant performance requirements. Dong et al. [12] proposed that the compressive strength of concrete cured at low temperatures could be greatly improved by adding compound and mineral admixtures, while Youjun et al. [13] conducted quantitative testing and analyses on factors influencing concrete strength under low curing temperatures and identified mineral admixture and additive reference values.

These studies used a standard concrete test block as their research subject. However, a CFST, particularly at larger diameters, is different from a simple concrete test block. Its strength formation at early hydration temperature is higher, and the concrete strength formation process takes place within the confined space of a steel tube. Researchers have yet to identify the strength characteristics of large-diameter CFST members under low curing temperatures.

The effects of different expansive agents on shrinkage performance of concrete were studied in this study. The results showed that the effect of $\mathrm{Ca}-\mathrm{Mg}$ expansive agent was better. The CFST specimen was taken as the research object in this study, and the curing temperature was strictly controlled, as well as the strength of concrete in different ages was tested. The CFST specimen in this study was large in size, which was in accordance with the actual bridge, and its ambient temperature was set very low. Concrete in pipes was sampled and tested according to Technical Specification for Testing Concrete Strength by the Core Drilling Method (JGJ T 384-2016). The results showed that insulated curing at low temperatures was beneficial to the strength of concrete. This study was developed with the intention of providing reference information for the construction of CFST-based concrete arch bridges in winter.

\section{Materials and Methods}

2.1. Testing Materials and Mechanical Properties. The concrete design strength was C55 grade. Test raw materials were as follows: P.II42.5 Portland cement; grade I fly ash; grade S95 blast furnace slag powder; microsilica powder; river sand; continuous graded macadam (coarse aggregate), from 5 to $20 \mathrm{~mm}$; PCA-I retarding, high-performance polycarboxylic acid water reducer, produced by Subote New
Material Co. Ltd; HME-II, high-performance concrete magnesium oxide composite expansive agent and calcium expansive agent, also produced by Jiangsu Subote New Materials Co. Ltd. By applying various expansive agents, three mixture ratio groups were created for experimentation, at the mixture ratios shown in Table 1 . The water cement ratio of three kinds of concrete was 0.393 . No expansive agent was added to \#1 concrete. Calcium expansive agent and $\mathrm{Ca}-\mathrm{Mg}$ composite expansive agent were added to $\# 2$ and \#3 concrete, respectively. The 28-day cubic compressive strengths of \#1, \#2, and \#3 concrete under standard curing conditions were 69.2,65.4, and 66.2 $\mathrm{MPa}$, respectively, with corresponding elastic moduli of $38.7,37.2$, and $37.6 \mathrm{GPa}$.

2.2. Deformation Performance Tests. Concrete deformation performance tests were carried out, including autogenous shrinkage tests at the plastic and hardening stages, a drying shrinkage test, and a limited deformation test. Autogenous shrinkage refers to the reduction in apparent volume of concrete, after pouring and forming under sealed conditions, and is caused by cement paste volume decrease during hydration. Drying shrinkage refers to the irreversible shrinkage caused by adsorptive water loss in internal pores and gel pores in unsaturated air and after concrete completes curing. A deformation test on shrinkage-compensated concrete, cured under limited conditions, is called a limited deformation test and is one of the important deformation performance indexes for shrinkage-compensated concrete.

In order to investigate concrete deformation performance, autogenous shrinkage (in plastic and hardening stages), drying shrinkage, and confined deformation were measured, in compliance with the following Chinese Technical Standards, as shown in Figure 1:

(i) The hydraulic concrete test rules (SL 352-2018)

(ii) The test method for long-term performance and durability of ordinary concrete (GB/T 50082-2009)

(iii) The technical specification for application of shrinkage compensating concrete (JGJ/T 283-2012)

In the autogenous shrinkage test of concrete at the plastic stage and hardening stage, plastic molds were used as containers so that shrinkage and expansion deformations could be measured and its deformation could not be limited. In the restricted deformation test, metal molds were used as containers so that its deformation in other directions could be restricted/limited better.

Testing for autogenous shrinkage at the plastic stage required hourly testing over a 25 -hour period. The autogenous shrinkage test during the hardening stage, the drying shrinkage test, and the limited deformation test all required daily testing, over 45 days, 45 days, and 60 days, respectively. The four tests were set up in three groups, with three specimens in each group.

2.3. Concrete Strength Testing in CFST. Mix ratio \#3 was chosen for this test, and the CFST member diameter was $1.6 \mathrm{~m}$, with specific dimensions as shown in Figure 2. 
TABLE 1: C55 concrete test mix ratios $\left(\mathrm{kg} / \mathrm{m}^{3}\right)$.

\begin{tabular}{|c|c|c|c|c|c|c|c|c|c|c|c|}
\hline Materials & Cement & Water & $\begin{array}{l}\text { Fly } \\
\text { ash }\end{array}$ & $\begin{array}{l}\text { Expansive } \\
\text { agent }\end{array}$ & $\begin{array}{l}\text { Mineral } \\
\text { powder }\end{array}$ & $\begin{array}{c}\text { Silica } \\
\text { powder }\end{array}$ & Sand & Stone & $\begin{array}{c}\text { Water reducing } \\
\text { agent }\end{array}$ & Total & Remarks \\
\hline$\# 1$ & 400 & 157 & 75 & 0 & 45 & 10 & 711 & 1052 & 10.60 & 2460.6 & Benchmark group \\
\hline$\# 2$ & 400 & 157 & 45 & 50 & 25 & 10 & 711 & 1052 & 10.60 & 2460.6 & Calcium expansive agent \\
\hline \#3 & 400 & 157 & 45 & 50 & 25 & 10 & 711 & 1052 & 10.60 & 2460.6 & $\begin{array}{l}\text { Ca-Mg composite } \\
\text { expansive agent }\end{array}$ \\
\hline
\end{tabular}

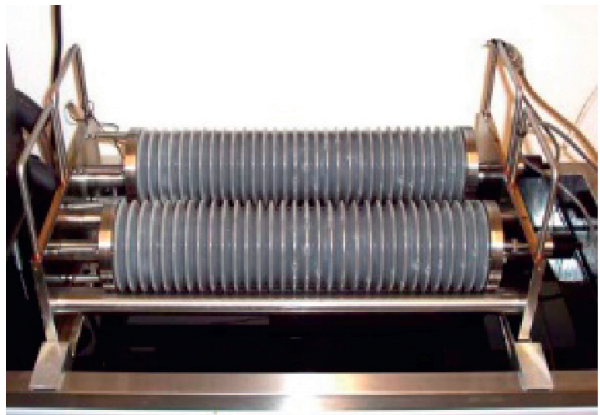

(a)

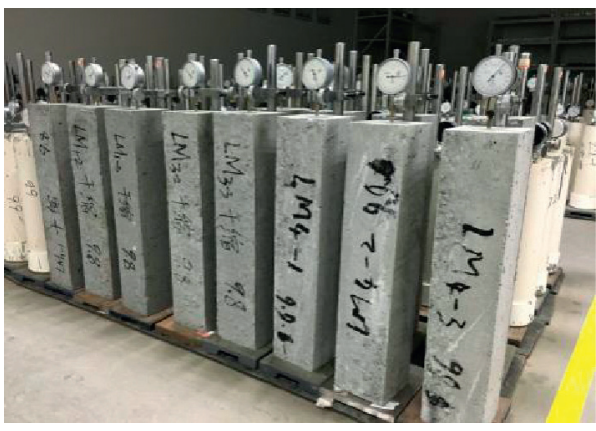

(c)

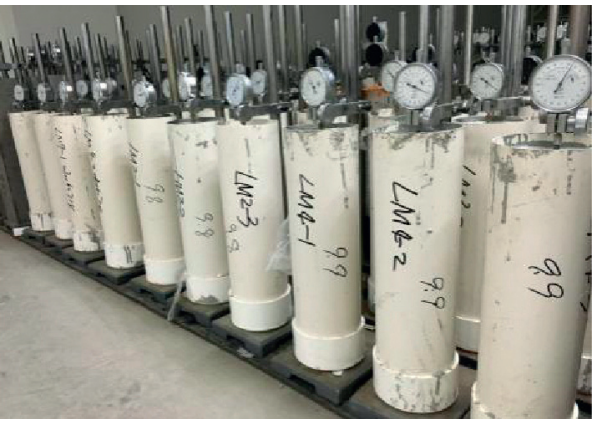

(b)

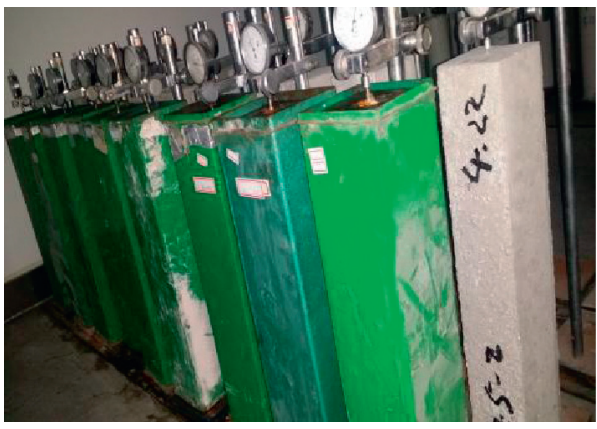

(d)

Figure 1: Concrete deformation performance tests. (a) Autogenous shrinkage test at the plastic stage. (b) Autogenous shrinkage test at the hardening stage. (c) Drying shrinkage test. (d) Restricted deformation test.

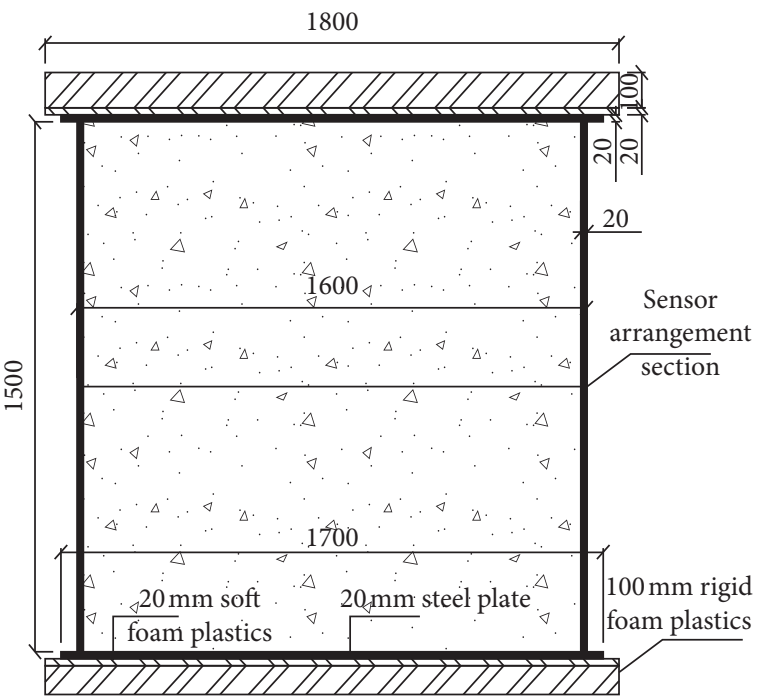

(a)

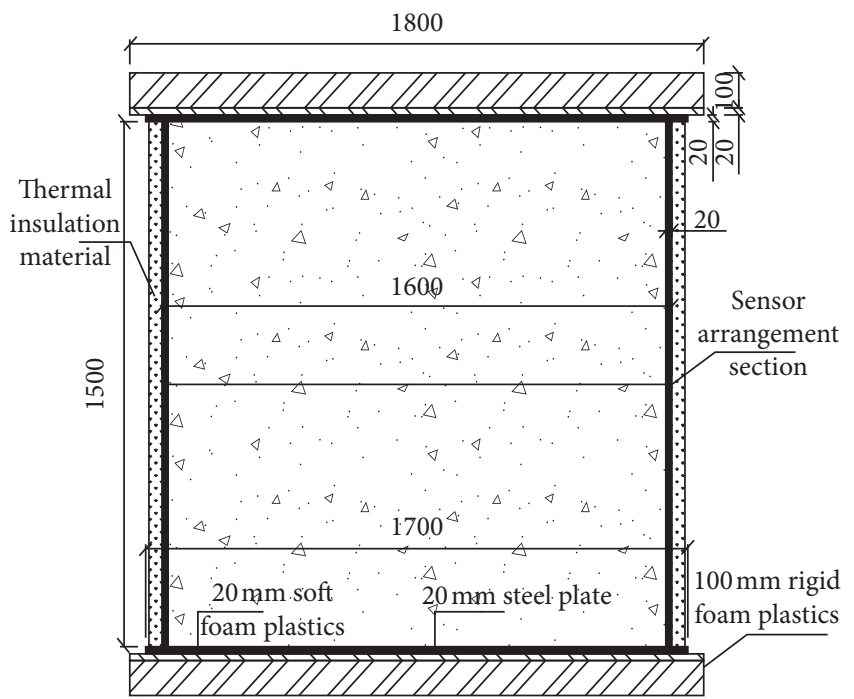

(b)

Figure 2: CFST member dimensions (mm). (a) CFST-1 (not insulated). (b) CFST-2 (insulated). 
Two groups of specimens were prepared, with one group wrapped with thermal insulation material during curing (CFST-2) and the other left unwrapped (CFST-1). The insulation material was $1.5-\mathrm{cm}$ thick cotton insulation.

The test pipe was placed in the temperature test box, shown in Figure 3 at a temperature of $0^{\circ} \mathrm{C}$. The test concrete was poured into the test steel tube, as shown in Figure 4, and then, the test box door was closed, and the temperature was maintained at $0^{\circ} \mathrm{C}$.

With the curing temperature set at $0^{\circ} \mathrm{C}$, concrete core samples were drilled at day 3 (d-3), d-5, d-7, d-11, d-14, d-28, $\mathrm{d}-42$, and $\mathrm{d}-56$, respectively, after pouring. Then, they were named " $1 \#$ to $8 \#$ " according to the drilling time, respectively. Two sample groups were taken at a time, with each group containing 3 specimens. While the Technical Specification for Testing Concrete Strength by the Core Drilling Method (JGJ T 384-2016) specifies $150 \mathrm{~mm}$ core sample specimens, it was considered that the compressive strength of $100 \mathrm{~mm}$ diameter core samples, with $1: 1$ height to diameter ratio, would be basically the same when it is given the same curing age and under the same conditions. So $100 \mathrm{~mm}$ diameter cylindrical core samples, with 1:1 height to diameter ratio, were withdrawn for testing.

The specimens were sampled and then tested under axial compression, with the drill core sampling positions shown in Figure 5.

In addition, the same-age standard cube specimens from the same batch of concrete in the standard curing environment were selected for compression testing for comparison.

Core and cube specimens were tested in compliance with the current National Standard Test Method for Mechanical Properties of Ordinary Concrete (GB/T50081). Representative core samples and standard curing samples can be seen in Figure 6.

2.4. Shrinkage Verification. Test sections were arranged in the middle of the two CFST members, in the positions shown in Figure 2. Temperature (thermistor-type) and stress (vibrating string-type) sensors were attached to the highstrength, insulated wire rope of the test section. Strain sensors could measure temperature and strain simultaneously. A wireless temperature acquisition system was used, with data acquired at 10 min intervals.

The measuring point layout is as shown in Figures 7 and 8 .

In order to verify concrete shrinkage, the CFST member was measured using an ultrasonic testing instrument (Model ZBL-U520) which was made by Beijing Zhibolian Science and Technology Co., Ltd. Two component cross sections at $90^{\circ}$ from each other were selected for testing, as shown in Figure 5(a). Two probes were placed close to the detection position, and the switch was opened. One probe emitted ultrasonic wave. The ultrasonic wave passed the detection section and was received by the other probe. The detector would display the propagation velocity. Testing was conducted at day 3 (d-3), d-5, d-7, d-11, d-14, d-28, d-42, and

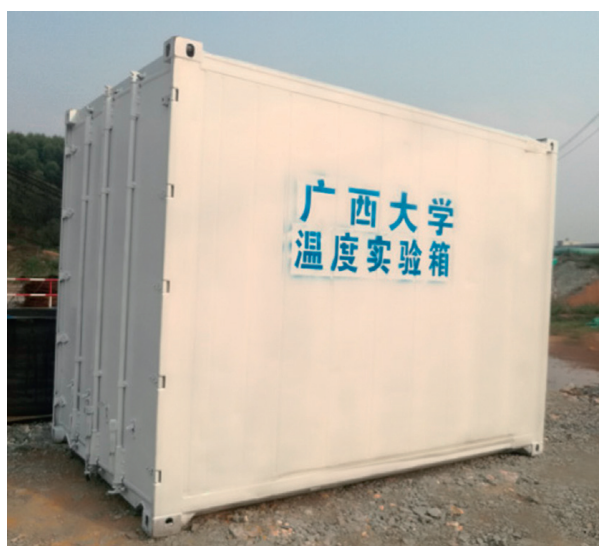

Figure 3: Temperature test box.

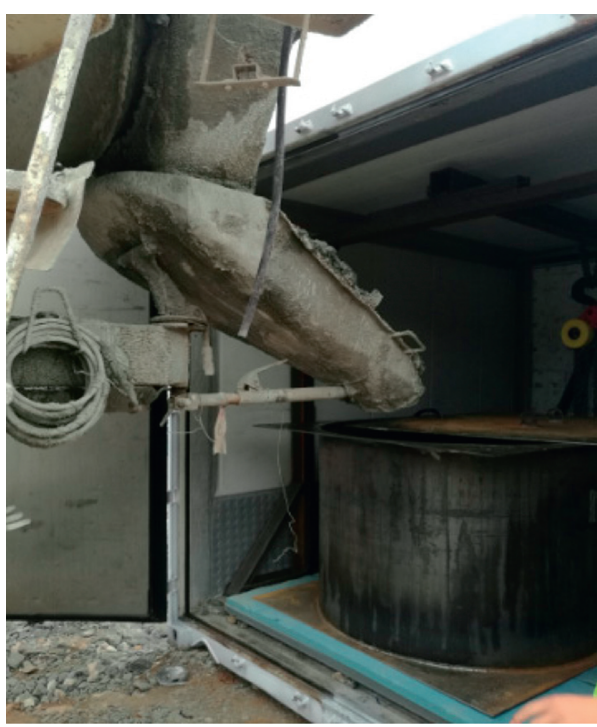

FIGURE 4: Concrete pouring process.

d-56, using a testing regime consistent with that used for testing concrete strength.

\section{Results and Analysis}

3.1. Deformation Performance. Experimental results for autogenous shrinkage at the plastic stage (before final setting) are shown in Figure 9(a), with the results from autogenous shrinkage at hardening stage (from final setting) shown in Figure 9(b) and the results for drying shrinkage and limited deformation shown in Figures $9(\mathrm{c})$ and $9(\mathrm{~d})$, respectively.

The shrinkage was positive, indicating the expansion of concrete. The shrinkage rate was negative, which indicates the shrinkage of concrete. When the concrete showed slight expansion, it was an ideal state. Some of the shrinkage results are comparable in Figure 9 and the difference is statistically insignificant.

It can be seen in Figure 9(a) that the concrete mixed with $\mathrm{Ca}-\mathrm{Mg}$ composite expansive agent (\#3) was expansive in the plastic stage, while the other two groups of concrete were 


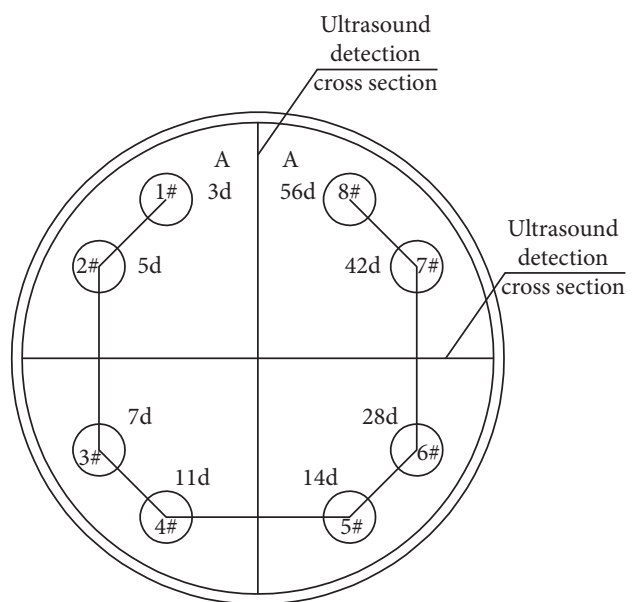

(a)

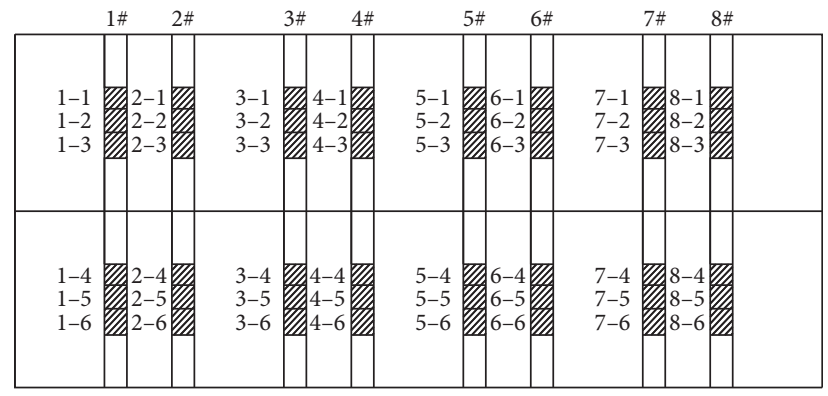

(b)

Figure 5: Core sampling positions. (a) Core arrangement for different age strength sampling. (b) A-A section.

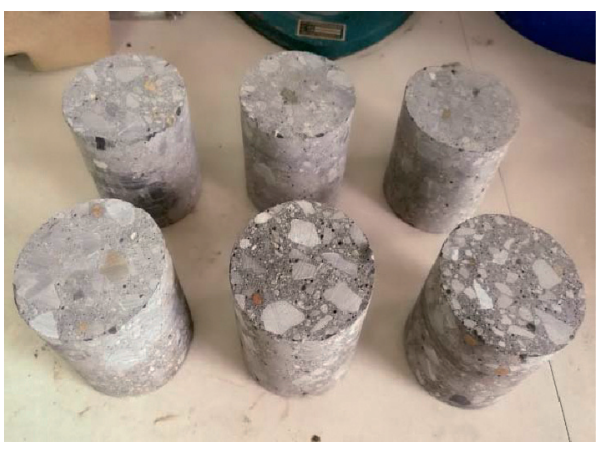

(a)

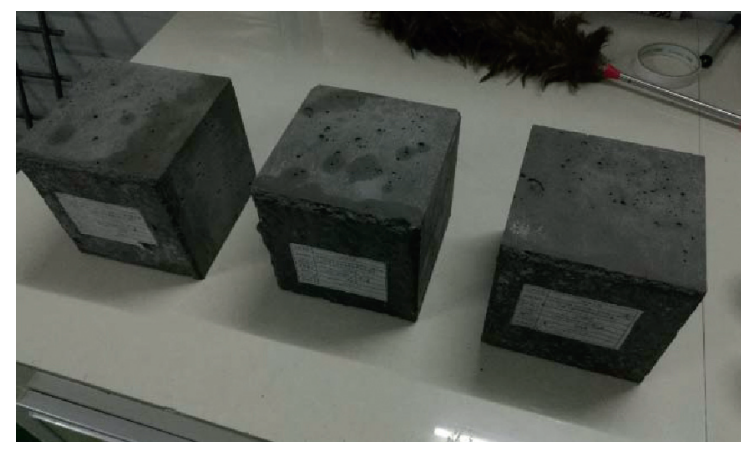

(b)

Figure 6: Core and cube samples for compression testing. (a) Core specimen. (b) Standard-maintained specimens.

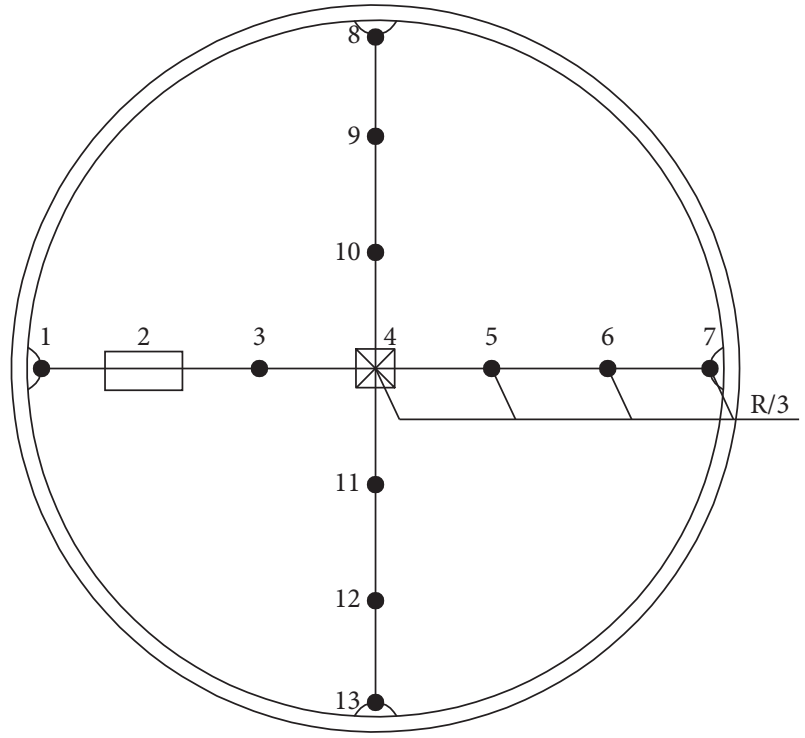

- Temperature sensor Xtrain sensor

Figure 7: Measuring point layout.

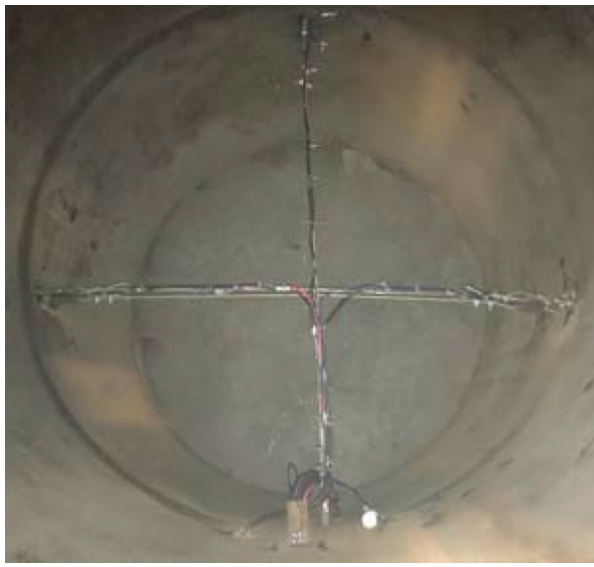

FIGURE 8: Placement of the sensors.

shrinking. From Figure 9(b), it could be seen that the autogenous volume deformation of concrete without expansive agent (\#1) was always negative in the hardening stage, while the concrete mixed with either $\mathrm{Ca}-\mathrm{Mg}(\# 3)$ or Ca composite expansive agent (\#2) was expansive. As shown in Figure 9(c), 


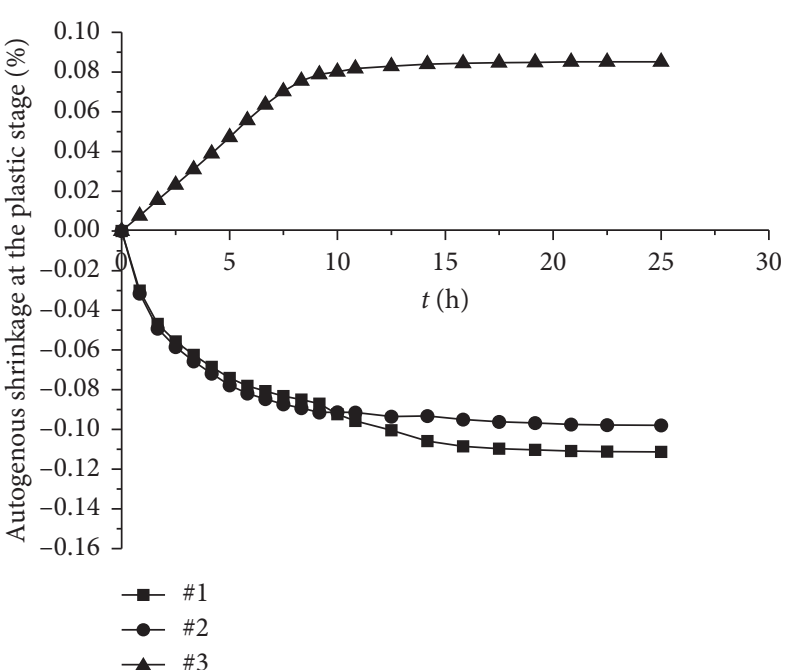

(a)

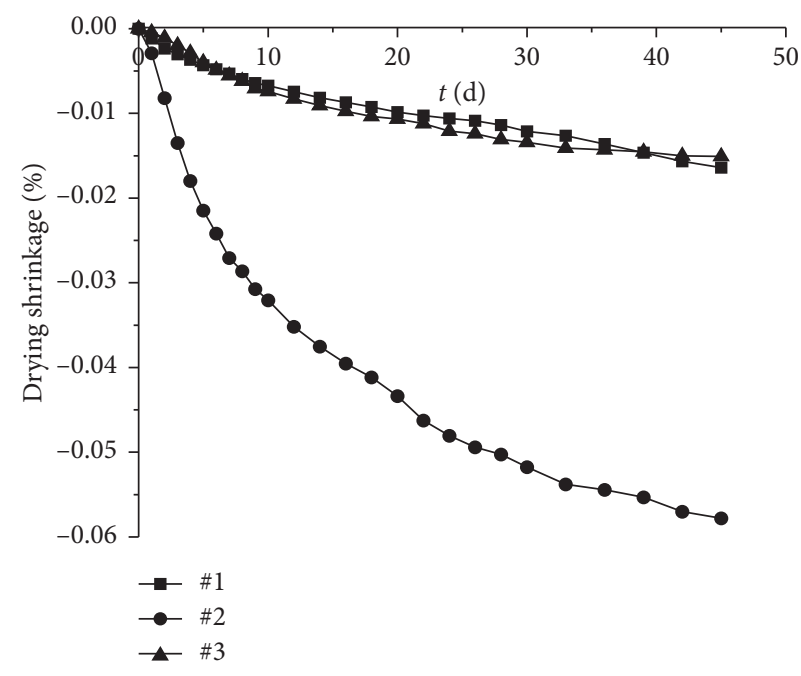

(c)

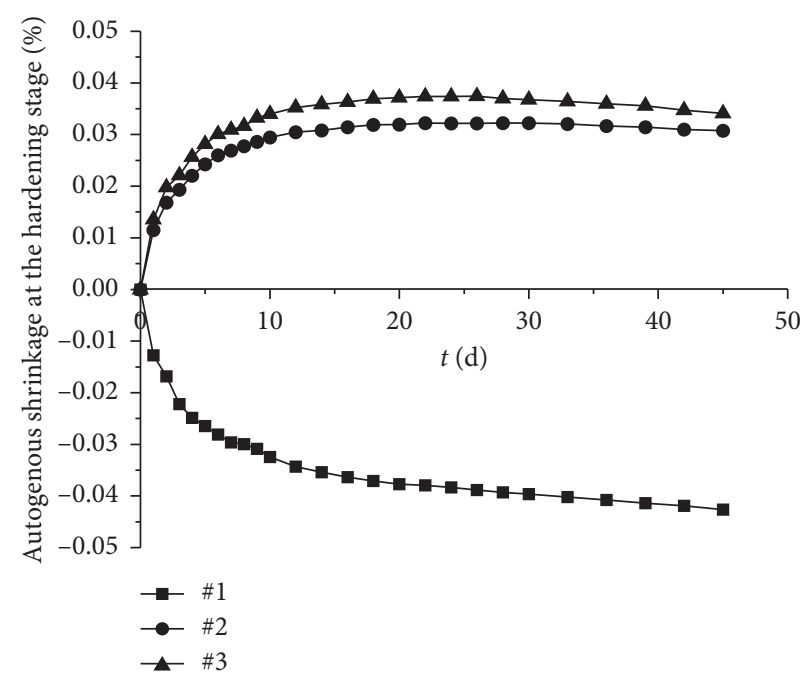

(b)

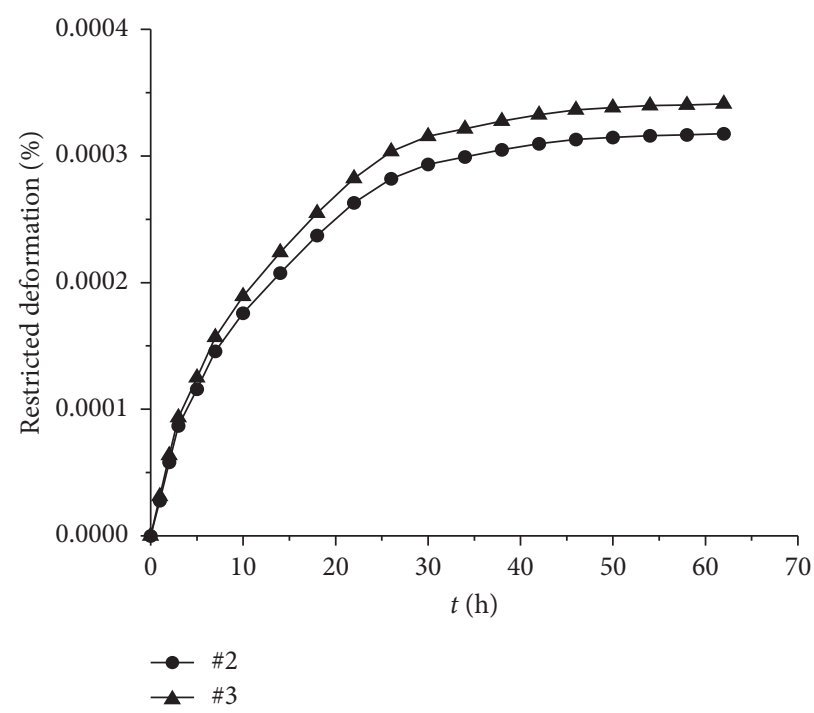

(d)

FIgURE 9: Volume stability test results for in-pipe concrete. (a) Autogenous shrinkage at the plastic stage. (b) Autogenous shrinkage at the hardening stage. (c) Drying shrinkage. (d) Restricted deformation.

the results showed that $\mathrm{Ca}-\mathrm{Mg}$ composite expansive agent performed better than Ca expansive agent during the drying shrinkage state. As shown in Figure 9(d), the concrete in the pipe was confined, resulting in expansion deformation; and the effect of $\mathrm{Ca}-\mathrm{Mg}$ composite expansive agent was better than that of $\mathrm{Ca}$ expansive agent. According to these results, the concrete with expansive agent shrinkage performance was better than that of concrete without expansive agent, and the effect of $\mathrm{Ca}-\mathrm{Mg}$ composite expansive agent was better than that of $\mathrm{Ca}$ expansive agent.

3.2. Concrete Compressive Strength in CFST. Results of concrete compressive strength in CFST are shown in Figure 10. CFST-2 was insulated and CFST-1 was not. The design strength of the concrete was C55, and the average strength in our testing of the standard cured specimens, at d-28, was 68.4 MPa. The average CFST-1 and CFST-2 core sample strengths, on d-28, were $50.3 \mathrm{MPa}$ and $56.5 \mathrm{MPa}$, respectively. Under the two curing conditions, the concrete strength development process was basically the same, with rapid strength development in the early stage, slowing down after d-14. For samples of the same age, concrete strength in CFST-1 was the lowest, followed by CFST-2, with concrete strength of the standard curing specimens the highest. The concrete strength in CFST-1, at d-28, was $91.5 \%$ of the design strength, and $73.5 \%$ of the standard curing concrete strength, while CFST-2 concrete strength, at d-28, reached the design strength, and achieved $82.6 \%$ of the standard curing concrete strength.

The concrete strength in CFST-1, without thermal insulation film, had not reached the design strength by d-28, while in CFST-2, using thermal insulation film, the concrete was significantly stronger by $\mathrm{d}-28$, reaching the design 


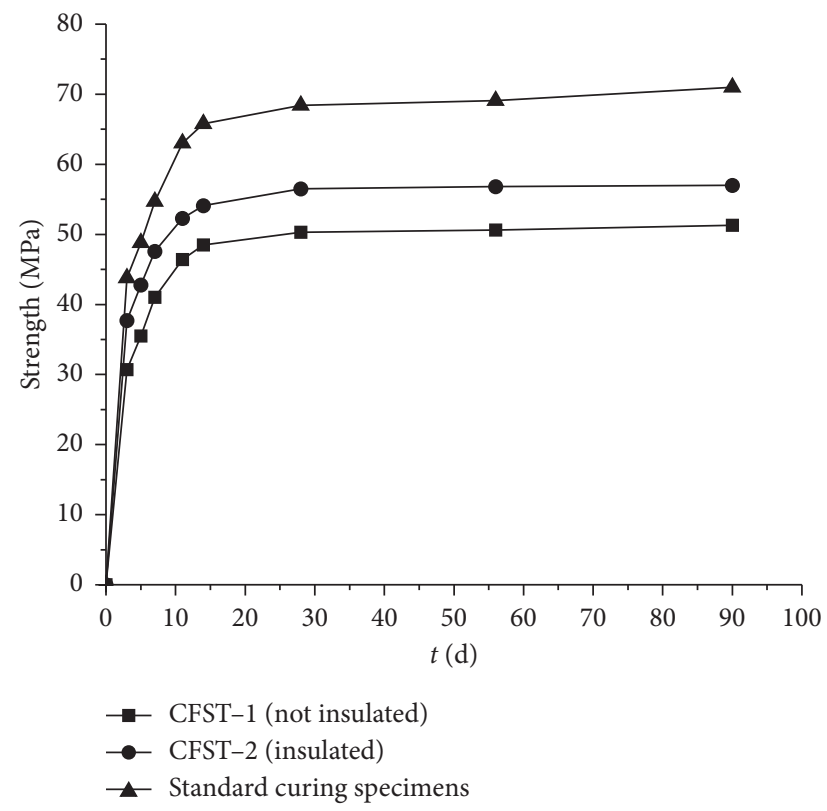

Figure 10: Concrete strength vs time.

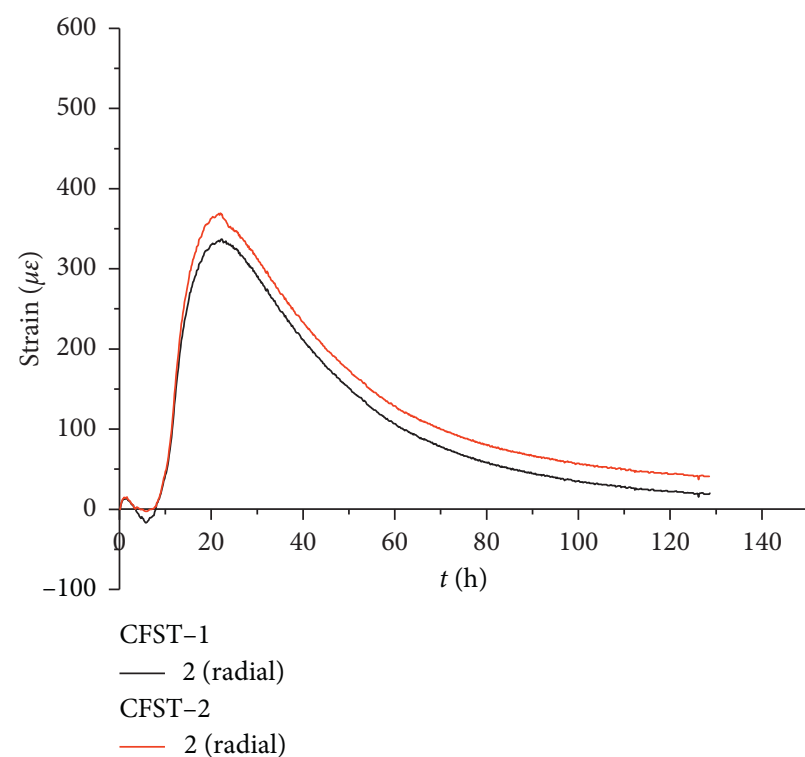

(a)

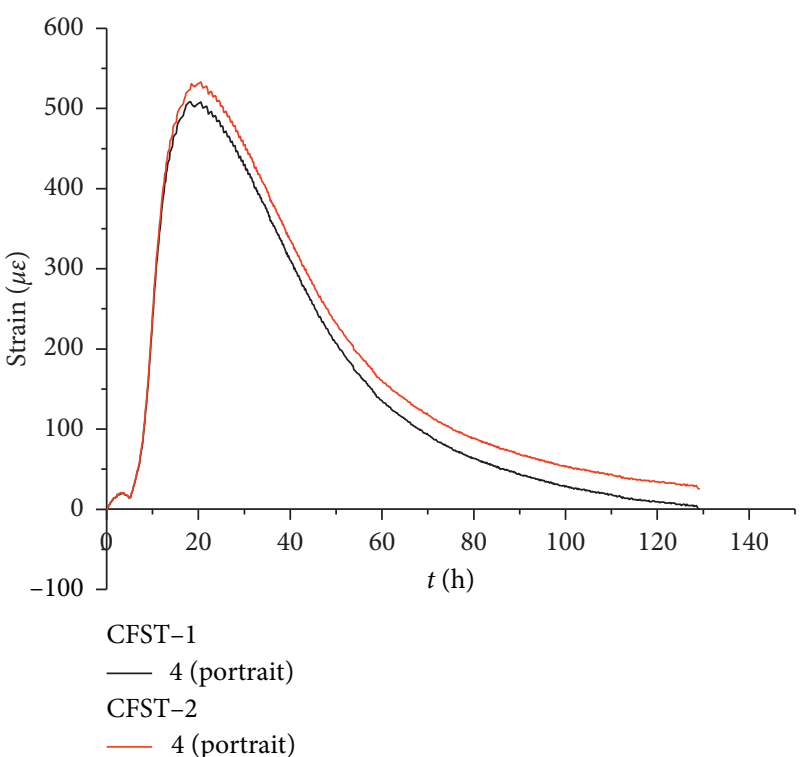

(b)

FIgURe 11: Strain vs time curve for in-pipe concrete. (a) Radial strain. (b) Portrait strain.

strength. Regarding the compressive strength performance, it was increased by $10 \%$. These results showed that the curing system involving thermal insulation film would enhance concrete strength under low-temperature condition and concrete strength met design requirements.

3.3. In-Pipe Concrete Shrinkage. The strain-time curve for inpipe concrete can be seen in Figure 11, with hydration heat vs time shown in Figure 12 and the ultrasonic test results displayed in Figure 13. The strain sensors were embedded vibrating string sensors, which could simultaneously measure temperature and strain. After installing the sensor and connecting the acquisition instrument, the temperature value could be automatically collected and the strain value after temperature compensation could be calculated continuously. When the initial strain was 0 and the final strain was positive, the concrete was in the state of expansion. If the final strain value was negative, the concrete was in the state of shrinkage. It can be seen from Figure 11 that under different curing conditions, the in-pipe concrete initially expanded and then shrank, with an increased hydration temperature and the final observations showing that it was still in a nonshrinkage state. The final strain in CFST-2 was larger than that in CFST-1, with 


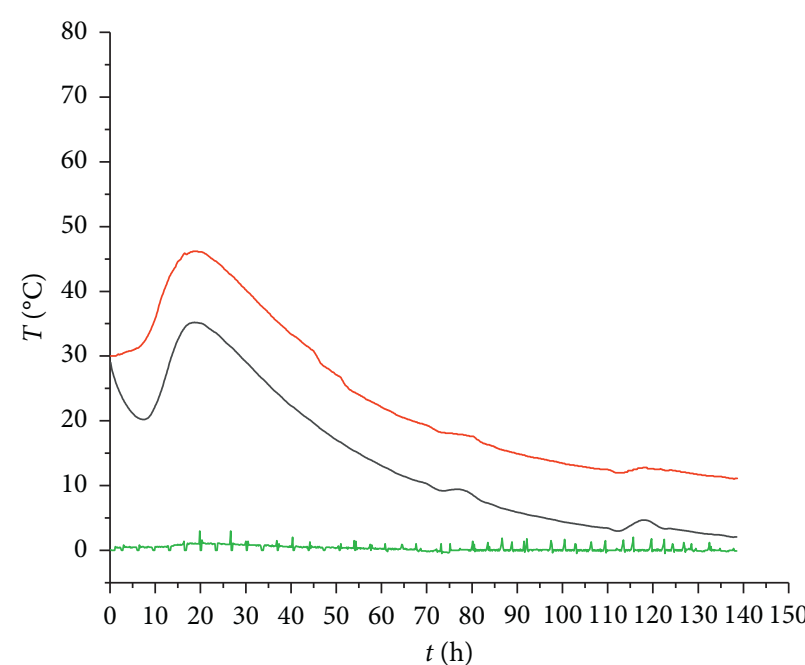

CFST-1

$-1$

Ambient temperature

0

CFST-2

$-1$

(a)

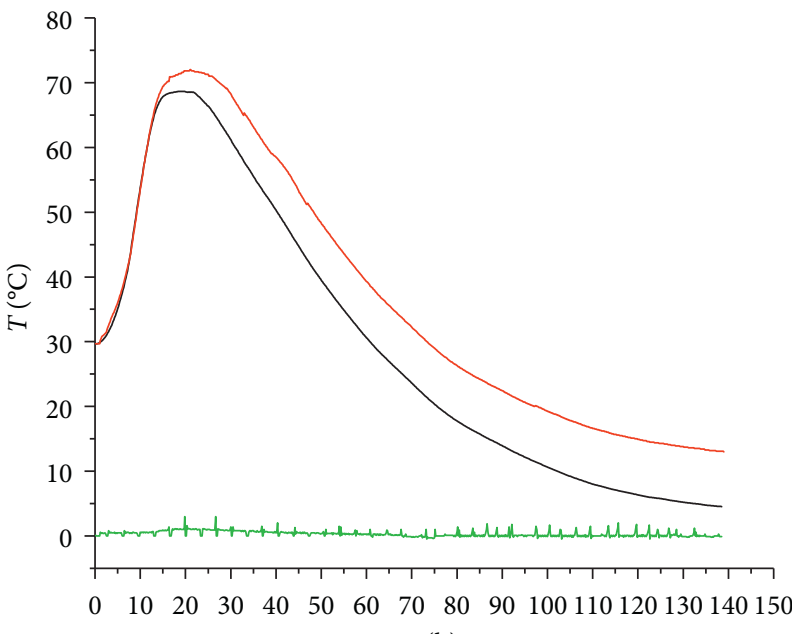

$t(\mathrm{~h})$

CFST-1

$-3$

Ambient temperature

0

CFST-2

$-3$

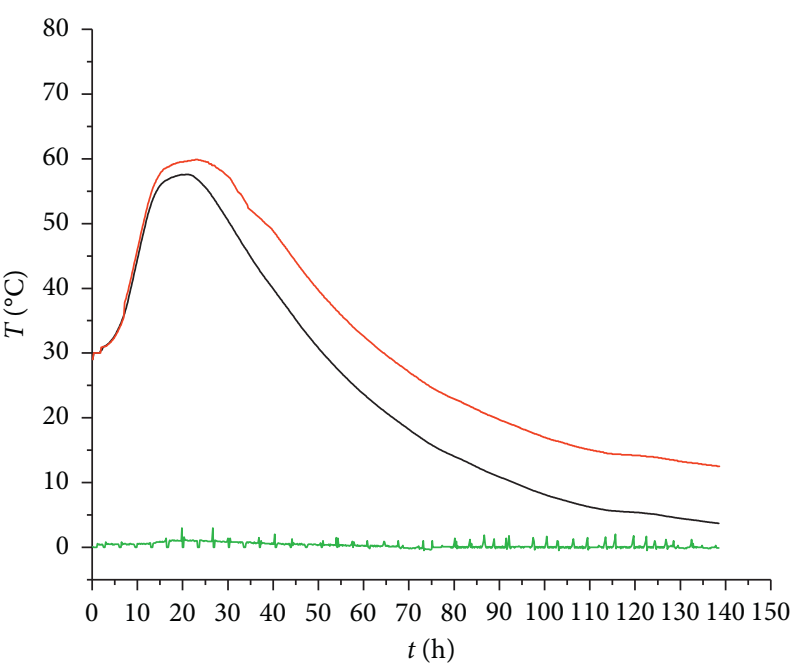

CFST-1

$-2$

Ambient temperature

- 0

CFST-2

$-2$

(b)

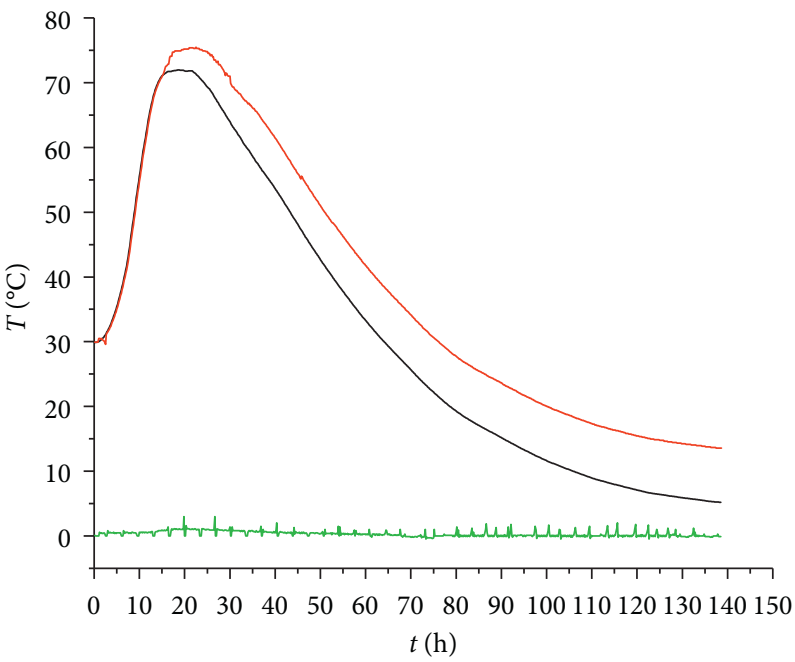

CFST-1

$-4$

Ambient temperature

- 0

CFST-2

$-4$

(c)

(d)

Figure 12: Hydration heat vs time for in-pipe concrete. (a) Point 1. (b) Point 2. (c) Point 3. (d) Point 4.

the final CFST-1 strain close to 0. This showed that the concrete in CFST-2, with thermal insulation film, had a certain expansion reserve, and that its performance was better. In Figure 13, it can be seen that ultrasonic testing of CFST-1 and CFST-2 concrete showed that the wave velocities had not decreased, retaining values at $4500 \mathrm{~m} / \mathrm{s}$, with that for CFST-2 concrete being slightly higher than that for CFST-1. These results showed that there had been no debonding or voiding at all during the entire CFST specimen pouring and curing processes.

Points 1 to point 4 in Figure 12 represented four temperature measurements along the radius direction, and their positions were shown in Figure 2. From Figure 12, it could be seen that the hydration heat behavior for a $1.6 \mathrm{~m}$ diameter 


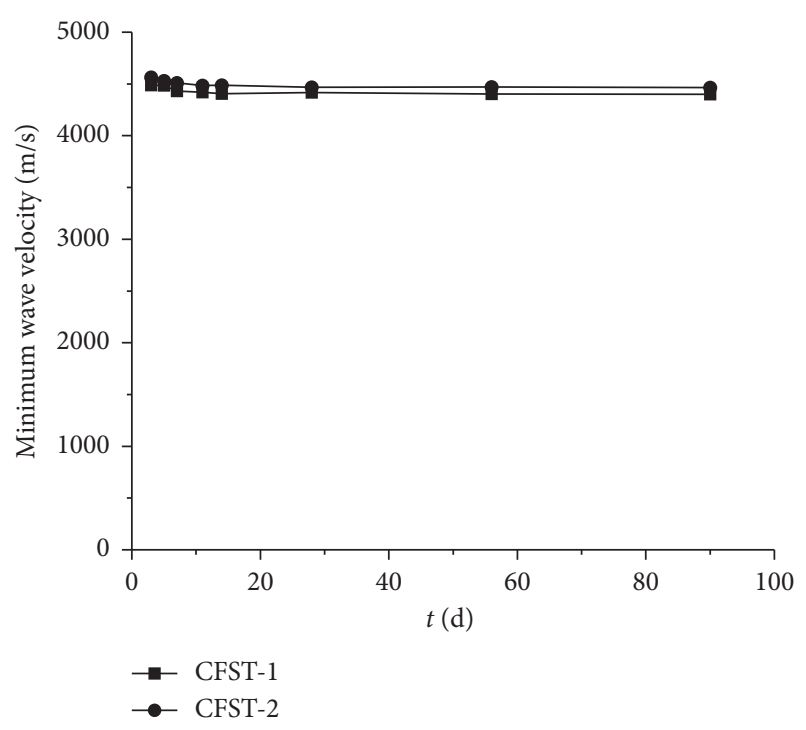

Figure 13: Velocity-time curve.

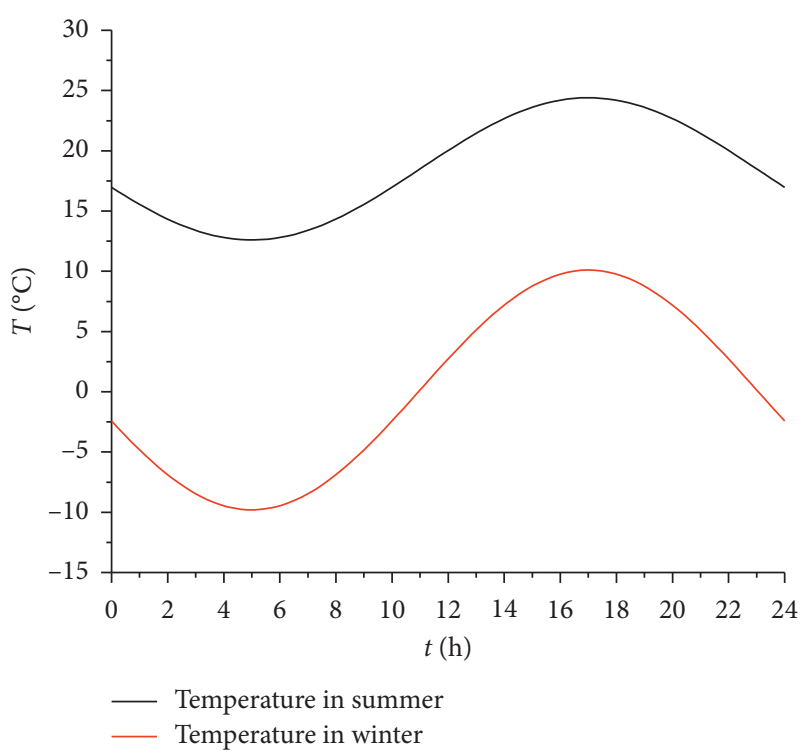

Figure 14: Temperature-time curve for Shannan (Tibet).

CFST specimen was similar to that of bulk concrete and that CFST hydration heat distribution was centrally symmetrical. Data from a quarter of the measuring points (points 1, 2, 3, and 4) were used to create Figure 12. At low temperatures, the in-pipe concrete temperature rose rapidly, for $10 \mathrm{~h}$, with the hydration heat temperature reaching its maximum at $20 \mathrm{~h}$; it then gradually decreased and eventually stabilized at ambient temperature. The two specimens had the same hydration heat rising stage, with the CFST-2 concrete cooling rate much lower than that of CFST-1.

The maximum temperature difference between the two specimens was at No. 4 measuring point, and the temperature rise for the marginal concrete in CFST-2 was much greater than that in CFST-1. The temperature difference between the inside and outside of CFST-2, with the thermal insulation film, was much smaller than that of CFST-1, and this smaller temperature difference contributed to the inpipe concrete shrinkage performance.

In-pipe concrete strength did not decrease abruptly under low-temperature curing at $0^{\circ} \mathrm{C}$. It is likely that the large-diameter CFST hydration heat provided sufficient temperature in the early stage of concrete strength formation to support formation of in-pipe concrete strength. In addition, in the CFST which had the heat preservation curing system applied, the concrete strength performance met concrete design requirements.

The construction schedule for concrete pumping in a CFST arch bridge should be selected according to site temperature, performance of concrete, and pumping time. When the pumping construction of a CFST arch bridge is in summer, in order to reduce the temperature difference between inside and outside hydration heat, it is necessary to be selective about construction time. Ideally, as hydration heat rises, ambient temperature should decrease, reaching its minimum when the hydration temperature was highest. Using a bridge in the Shannan area of Tibet as an example, the ambient temperature there can be seen in Figure 14, with the ambient temperature minimum between 04:00 and 06: 00 . Assume that pumping time (T1) lasted $10 \mathrm{~h}$ and hydration temperature reached maximum in 20 hours (T2). We could get the time to start pumping concrete by subtracting $\mathrm{T} 1$ and $\mathrm{T} 2$ from the time at the lowest temperature. The starting time was 22:00-24:00, so that it would be recommended that pumping construction takes place at night in summer. In winter, it is necessary to ensure there is sufficient temperature for concrete strength development. Ideally, as hydration heat rises, ambient temperature should also rise and that the time of the ambient temperature maximum should coincide with that of the hydration heat. The measured maximum temperature of the bridge site occurred between 16:00-18:00. So, assuming that pumping construction time lasted $10 \mathrm{~h}$, the starting time was 10 : 00-12:00, and therefore, it is recommended that pumping construction in winter takes place during the day.

\section{Conclusions}

(1) Shrinkage performance of the two groups of concrete samples with expansive agents was better than that without them, and the $\mathrm{Ca}-\mathrm{Mg}$ composite expansive agent was more effective than the $\mathrm{Ca}$ expansive agent.

(2) Under low-temperature $\left(0^{\circ} \mathrm{C}\right)$ curing, both the strength and shrinkage performance were better for the CFST protected with thermal insulation film. Regarding the compressive strength performance, it was increased by $10 \%$, reaching the required design strength.

(3) The construction schedule for concrete pumping in a CFST arch bridge should be selected according to site temperature, performance of concrete, and pumping time.

(4) Ca-Mg composite expansive agent, combined with a curing system using thermal insulation film, is 
recommended for use in low-temperature CFST arch bridge concrete pumping construction in the Tibet region.

\section{Data Availability}

The data used to support the findings of this study are included within the supplementary materials.

\section{Disclosure}

The funders had no role in the design of the study; in the collection, analyses, or interpretation of data; in the writing of the manuscript, or in the decision to publish the results.

\section{Conflicts of Interest}

The authors declare that there are no conflicts of interest.

\section{Acknowledgments}

The authors would like to thank Guangxi Road and Bridge Engineering Group Co., Ltd. for materials used for experiments and Editage (http://www.editage.cn) for English language editing. This research was funded by the Science and Technology Research and Development Plan Project of China Railway Corporation (Grant no. 2017G006-B), National Natural Science Foundation of China (Grant nos. 51738004, 51868006, and 51878186), Cultivation Project Jointly Funded by Guangxi Natural Science Foundation (Grant no. 2018GXNSFAA138067), Guangxi Science and Technology Plan Project (Grant no. AB17292018), Guangxi Innovation Driven Project (Grant no. AA18118029), and High-level Innovation Team and Outstanding Scholar Plan of Guangxi High Colleges.

\section{Supplementary Materials}

Figure 11: concrete strain analysis. Figure 12: concrete hydration temperature analysis. (Supplementary Materials)

\section{References}

[1] J. Zheng, "Development and prospect of long span arch bridges," China Journal of Highway and Transport, vol. 3, pp. 41-42, 2017, in Chinese.

[2] J. Zheng and J. Wang, "Concrete-filled steel tube arch bridges in China," Engineering, vol. 4, no. 1, pp. 143-155, 2018.

[3] J. Zheng and J. Wang, "Vacuum-assisted process test for concrete filled steel tube arch section," China Journal of Highway and Transport, vol. 27, no. 6, pp. 44-50, 2014, in Chinese.

[4] H. Marzouk and A. Hussein, "Effect of curing age on highstrength concrete at low temperatures," Journal of Materials in Civil Engineering, vol. 7, no. 3, pp. 161-167, 1995.

[5] J. M. Khatib, "Low temperature curing of metakaolin concrete," Journal of Materials in Civil Engineering, vol. 21, no. 8, pp. 362-367, 2009.

[6] L. A. Barna, P. M. Seman, and C. J. Korhonen, "Energy-efficient approach to cold-weather concreting," Journal of Materials in Civil Engineering, vol. 23, no. 11, pp. 1544-1551, 2011.
[7] N. C. Consoli, C. G. da Rocha, and C. Silvani, "Effect of curing temperature on the strength of sand, coal fly ash, and lime blends," Journal of Materials in Civil Engineering, vol. 26, no. 8, Article ID 06014015, 2014.

[8] H. El-Hassan, E. Shehab, and A. Al-Sallamin, "Influence of different curing regimes on the performance and microstructure of alkali-activated slag concrete," Journal of Materials in Civil Engineering, vol. 30, no. 9, Article ID 04018230, 2018.

[9] D. Zhang, X. Cai, and L. Hu, "Effect of curing temperature on hydration of calcium aluminate cement-calcium sulfatelimestone system," Journal of Materials in Civil Engineering, vol. 30, no. 9, Article ID 06018011, 2018.

[10] C. Korhonen, "New developments in cold-weather concreting," in Proceedings of the 11th International Conference on Cold Regions Engineering, Anchorage, AK, USA, 2002.

[11] S. Jiang, X. Guan, S. Dong, and W. Zhu, "The application of C50 negative temperature concrete in bridge engineering," in Proceedings of the Fourth International Conference on Transportation Engineering, Chengdu, China, 2013.

[12] S. Dong, D. Feng, S. Jiang, and W. Zhu, "Effect of new type antifreeze agent on the mechanical behavior of negative temperature concrete," in Proceedings of the Fourth International Conference on Transportation Engineering, Chengdu, China, 2013.

[13] X. Youjun, L. Wei, L. Baoju, and F. Xing, "Early strength concrete compressive strength test in Qinghai-Tibet railway at low temperatures," Bridge Constructor, vol. 304, no. 2, pp. 27-31, 2003, in Chinese. 